\title{
40 anos da Pós-graduação da EEFE-USP: sua contribuição para a formação de recursos humanos para a docência no ensino superior
}

http://dx.doi.org/10.11606/1807-55092017000nesp089

\author{
Flávia da Cunha BASTOS* \\ Márcia Regina de SÁ* \\ Ary José ROCCO JUNIOR*
}

\section{Contextualizando}

Dentre os objetivos dos Cursos de Pós-Graduação no país a formação de recursos humanos para a docência tem sido discutida recentemente no âmbito acadêmico da Educação Física e do Esporte e na própria Coordenação de Aperfeiçoamento de Pessoal de Nível Superior (CAPES), órgão responsável pelos cursos de pós-graduação "stricto sensu" (mestrado e doutorado) em todo o Brasil ${ }^{1-2}$.

No processo de criação da Pós-Graduação da Escola de Educação Física e Esporte da Universidade de São Paulo (EEFE-USP), o objetivo de atuar no sentido da formação de docentes para o ensino superior foi manifestado como "formação e habilitação de docentes destinados ao ensino superior e pesquisadores de nível qualificado no campo da Educaçáo Física e Desportos".

Esse objetivo tem sido perseguido nessas quatro décadas de existência do Programa, que desde sua implantação até 2016 formou 538 mestres e 169 doutores.

Um dos meios para avaliar os programas se dá através do acompanhamento da atuação profissional dos egressos. A necessidade da avaliação é reforçada por $\mathrm{AMADIO}^{3}$, ex-diretor da EEFE-USP, que afirmou que a contribuição do sistema de pós-graduação se dá pela capacitação e titulação do docente.

\section{A pós-graduação é um sistema dinâmico e para ser acompanhado de forma eficiente, esse sistema deve ser permanentemente avaliado a fim de termos subsídios para uma constante análise reflexiva, controle e, se necessário, implementar modificaçôes que tragam ajustes para uma melhor adequação contextualizada dos processos e desenvolvimentos na pós-graduação. Esses fatores estáo perfeitamente integrados com a sistemática da pós-graduação na EEFEUSP (p.36).}

No país, o acompanhamento e avaliação dos egressos quanto a sua atuação profissional é considerada no documento da Área da CAPES $^{1}$ no que se refere ao processo de avaliação dos Cursos no país, mas não expressamente. Nesse documento não consta a expressão Egressos, no entanto no tópico referente a avaliação dos Docentes e da Inserção Social dos programas, são destacados:

2.4. Contribuição dos docentes para atividades de ensino e/ou de pesquisa na graduação, com atenção tanto à repercussão que este item pode ter na formação de futuros ingressantes na PG, quanto (conforme a área) na formação de profissionais mais capacitados no plano da graduação.

2.4.1. Observar a proporção de docentes que atuam em cursos de graduaçáo (docência); (...)

\section{Inserção Social}

5.1. Inserção e impacto regional e (ou) nacional do programa.

Avaliar:

Impacto educacional do Programa contribuição para a melhoria do ensino fundamental e médio, cursos de graduação e técnico/profissional e para o desenvolvimento de propostas inovadoras de ensino; geraçáo pelo Programa de "livros-textos" e outros materiais didáticos para a graduação bem como para o ensino fundamental e médio.

É possível observar, pelo exposto acima, que a CAPES, em seus documentos oficiais, valoriza a contribuição dos cursos de Pós-graduação em todo o país pela sua capacidade de formar docentes para atuarem em Instituiçóes de Ensino Superior (IES), e, também, para trabalharem como agentes de disseminação de conhecimento em diversas regióes do Brasil.

Em 2016, o tema foi tratado na mesa-redonda "A Avaliação e o Impacto Social da Pós-graduação", realizada em Manaus (AM), como parte da programaçáo do XXXII Encontro Nacional de Pró-reitores de 
pesquisa e pós-graduação (Enprop). Na ocasião, a PróReitora de pesquisa da Universidade Estadual Paulista (Unesp), Maria José Soares Mendes Giannini, ressaltou a importância de as instituiçóes tratarem o tema, independentemente das açóes da CAPES ${ }^{4}$.

No mesmo evento, representante da CAPES considerou que embora o tema esteja relacionado a aspectos da inserçâo social do programa, este item possui diferentes abordagens e formas de interpretaçôes e que, por isso, há a necessidade de aprofundamento da discussão sobre o tema.

O meio acadêmico também tem se dedicado ao tema, em termos críticos, destacando a valorização excessiva do enfoque à pesquisa, à ciência e à tecnologia em detrimento da formação de recursos humanos. Moreira e Tojal ${ }^{2}$ ressaltam a pouca discussão acerca da formação e do favorecimento mais explícito do docente do ensino superior. Enfatizam ainda a necessidade de se preparar efetivamente o profissional para o exercício da docência.

Movimento análogo tem se dado em diferentes áreas, no sentido de se valer de informaçóes e dados para avaliar a trajetória de egressos de cursos de diferentes especialidades. Na Medicina, um exemplo é o estudo de Schanaider ${ }^{5}$, que buscou avaliar o sistema de mapeamento dos egressos dos Programas de Pós-Graduação da área Medicina III da CAPES. $\mathrm{Na}$ pesquisa, foi constatada a escassez de dados em relação a avaliação dos egressos, junto a maior parte dos Programas, e o autor considerou que o sistema vigente para mapeamento de egressos necessita de padronização e suporte institucional e que seria necessária a elaboração de instrumento universal para os cursos da área no País e sugeriu a criação de um Programa Nacional de Egressos, objetivando consolidar diretrizes para o mapeamento dos egressos dos Programas de Pós-Graduação em Cirurgia no país.

Instituiçõos de ensino públicas e privadas que mantém programas de Pós-Graduação realizam e divulgam pesquisas institucionais relativas a seus egressos. A Fundação Getúlio Vargas acompanha as percepções dos egressos dos programas das áreas de História, Política e Bens Culturais ${ }^{6}$. A Universidade Federal do Paraná mantem o Programa de Egressos que acompanha os egressos dos cursos de Administração por meio de pesquisas, contatos individuais e acompanhamento dos Currículos Lattes ${ }^{7}$. Outros exemplos são o da Universidade de Brasília, que apresenta pesquisa sobre os egressos do curso PPG-Arte ${ }^{8}$, e da Universidade Federal da Bahia, que realiza e apresenta estudos acerca dos egressos do PPG de Educação?.
Outra tendência é a realização de trabalhos acadêmicos sobre egressos de programas de diferentes áreas recentemente. Especificamente quanto a requisitos para a docência de egressos de programas de doutorado em Administraçáo de universidades federais, Rissi e Silvestre Filho ${ }^{10}$ traçaram o perfil desses egressos a partir de pesquisa de campo, enquanto ParizotTo et al. ${ }^{11}$ o fizeram através de levantamento junto a Currículo Lattes de egressos na área de Odontopediatria.

Todos esses estudos e informações institucionais destacam que a maioria dos egressos atua na docência do ensino superior e técnico, revelando o cumprimento de um dos objetivos dos cursos de pós-graduação "stricto sensu" no país.

A produção de conhecimento acerca do tema revela uma tendência no sentido de se avaliar o processo como um todo e especificamente a inserção dos egressos na docência também em relação a Programas de Educação Física.

Estudos relativos a programas da área de Educação Física e Esporte também têm sido realizados com diferentes objetivos e abordagens. Em 2012, foi apresentada uma análise qualitativa das prioridades do processo formativo estabelecidas de 13 cursos oferecidos por universidades públicas e privadas brasileiras a partir da visão de egressos entre os anos de 2001 e 2006, concluindo-se que os Programas de Pós-Graduação em Educação Física precisam se dedicar mais ao processo de formaçáo dos professores para o nível superior ${ }^{2}$.

O estudo de SÁ $^{12}$ levantou dados sobre a atuação dos egressos ao analisar a qualidade do ensino no Programa de Pós-Graduação da Escola de Educação Física e Esporte da Universidade de Sáo Paulo, no período de 1979 a 2007, indicando na ocasião dos 30 anos do Programa que a maioria dos egressos exercia a função professor de instituição de ensino superior.

Mais recentemente, em nível de Mestrado, estudo do perfil do egresso dos dois programas na área em funcionamento no Estado do Rio Grande do Sul (RS) teve como um dos focos analisar a atuaçáo profissional dos egressos, antes, durante e após a conclusão do mestrado ${ }^{13}$.

Em relaçáo a programa de Doutorado, a análise do processo de migraçáo acadêmica de egressos das primeiras turmas dos Programas de Pós-Graduação em Educaçáo Física de universidades da Região Sul do Brasil indica a migração no sentido da atuação em universidades públicas, reforçando a importância desse monitoramento para a gestão dos Programas no país ${ }^{14}$. 
Esses estudos revelam porcentuais de inserção dos egressos relevantes, tanto nas universidades/ faculdades públicas como nas instituições de ensino privadas, demonstrando a relevância dos programas para a formação de recursos humanos para atuarem no ensino superior.

\section{A docência no ensino superior em Educação Física e Esporte: a contribuição da EEFE-USP para a formação de recursos humanos}

O Programa de Pós-Graduação da EEFE-USP, desde a sua criação, em 1977 , até 2016 , registra
707 títulos de Mestre e Doutor (FIGURA 1), outorgados a 625 pessoas (FIGURA 2):

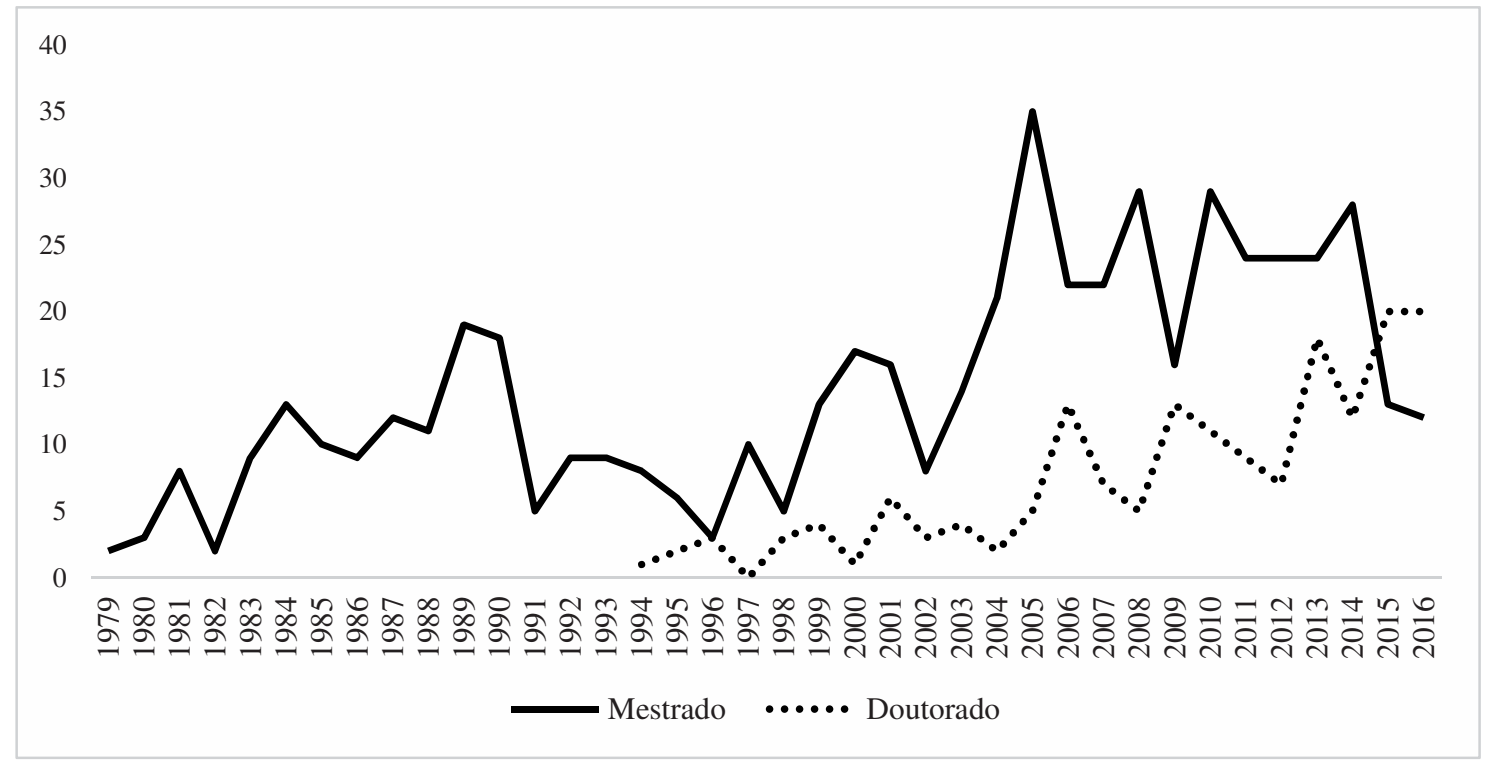

FIGURA 1 - Títulos de Mestre e Doutor outorgados (1979-2016).

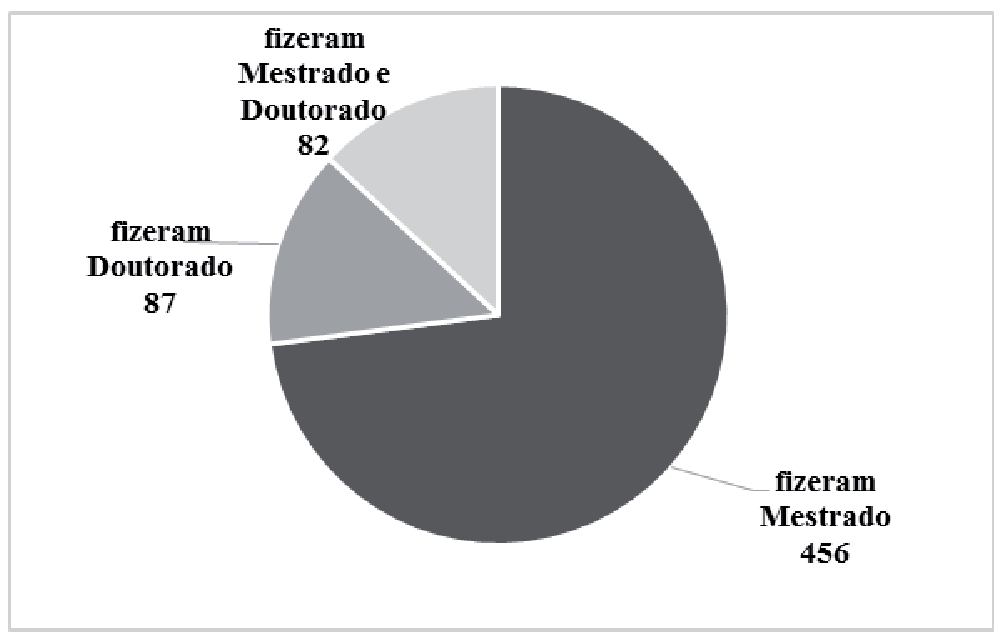

FIGURA 2 - Pessoas tituladas (Mestrado e Doutorado). 
Nesse momento em que o Programa atinge os 40 anos de existência e que o tema tem sido discutido nacionalmente, a instituição considerou relevante realizar uma nova avaliação junto aos seus egressos, no sentido de analisar a evolução e os rumos do Programa em termos da sua inserçáo social, especificamente no que diz respeito ao engajamento dos egressos no ensino superior.

Para tanto, foi elaborado um instrumento, com base no questionário desenvolvido por $\mathrm{SA}^{12}$. O mesmo foi enviado a 625 pessoas (dentre os quais $12 \%$ estão aposentados), sendo que 456 fizeram só o mestrado; oito, só o doutorado e 82 fizeram mestrado e doutorado (esses responderam só um vez). Foram obtidas 262 respostas (42\%).

Quanto a motivação para realizar a Pós-graduação, foram levantadas as respostas relativas as alternativas dos respondentes (até três razóes) (FIGURA 3). Destaca-se o Aprimoramento de conhecimentos e o interesse em Pesquisa. Esses resultados demonstram que o interesse em ingressar na carreira docente não se evidencia prevalentemente quanto ao ingresso na carreira docente, diferentemente do verificado no levantamento realizado há 10 anos, junto a 155 egressos (123 do Mestrado e 32 do Doutorado ${ }^{12}$. Na ocasião, a carreira acadêmica era a maior motivaçáo declarada, em conjunto com possibilidade de atuaçáo na pesquisa.

Dessa forma, se analisarmos o conjunto das opções relativas a esses temas (nesse levantamento em tópicos separados), podemos considerar que o cenário permanece o mesmo. A motivação para o aperfeiçoamento profissional (conhecimento e titulação) atende a demanda das IES, especialmente as públicas, para as quais a titulação é requisito para ingresso.

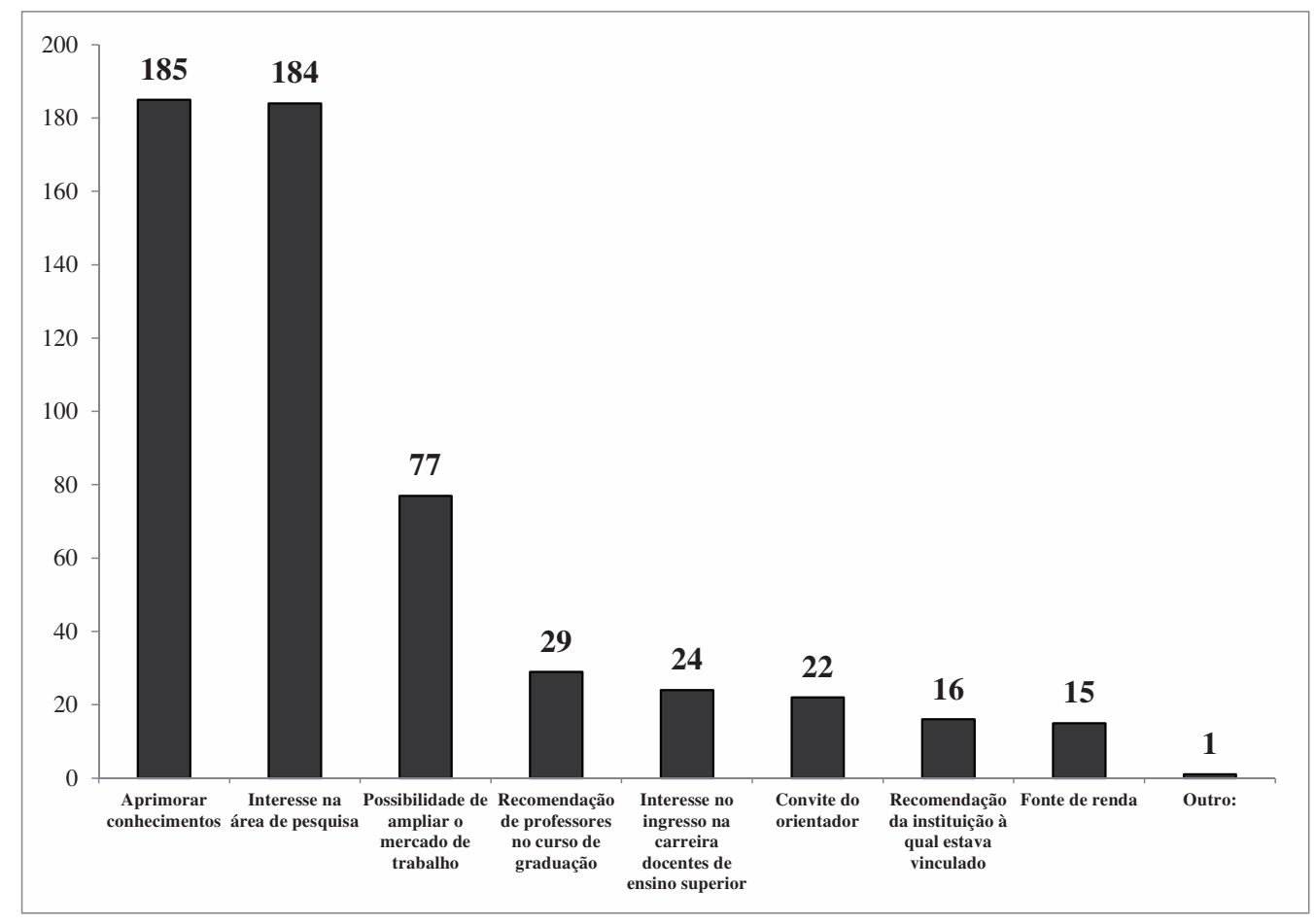

FIGURA 3 - Razões que influenciaram na decisão de ingressar na Pós-graduação.

Importante mencionar que diversos outros fatores relacionados à docência, como "possibilidade de ampliar o mercado de trabalho", "interesse no ingresso na carreira docente de ensino superior" e "recomendação da instituiçáo a qual estava vinculado", também funcionaram como elementos de estímulo para o ingresso na pós-graduação.

Quanto a situaçáo atual em relação às atividades profissionais desenvolvidas após a conclusão da pós-graduação, $65 \%$ indicam que atuam em
Instituição de Ensino Superior (FIGURA 4). O resultado é semelhante ao obtidos em estudos da área de Educaçấo Física - $78,7 \%{ }^{12} ; 62,4 \%$ atuavam na docência, tanto em nível superior como básico ${ }^{13}$ e no estudo de Gentil e Nascimento ${ }^{14}$, que concluíram que dentre os que obtiveram o título de doutor além de estabilizarem-se em instituiçóes públicas federais ou estaduais, ingressaram no ensino superior na regiáo onde eles concluíram seu curso de doutorado. Os autores ressaltam ainda 
que parcela considerável de estudantes que estavam em instituições superiores privadas no período da realização do doutorado, com a obtenção do título, migraram para as universidades públicas.

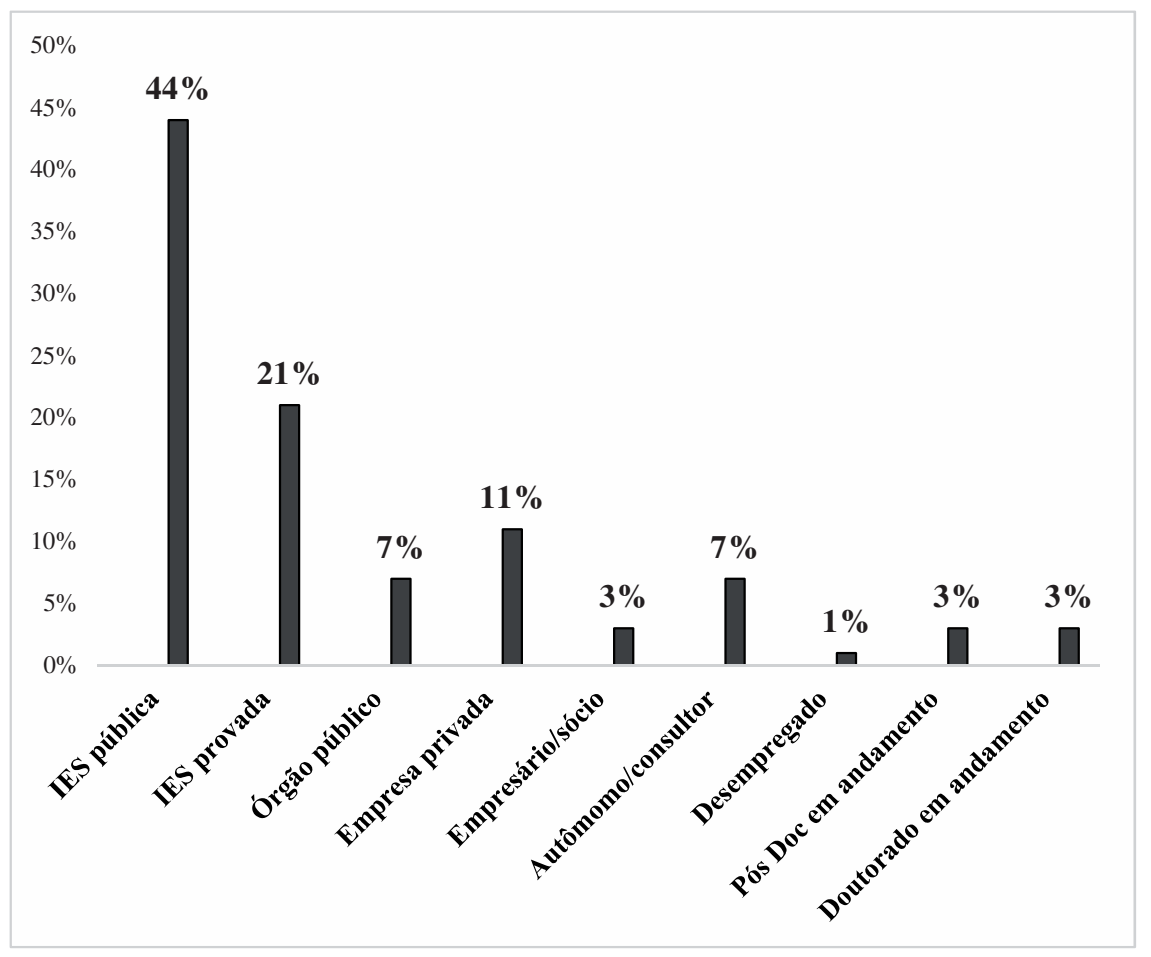

FIGURA 4 - Porcentuais de principal atividade profissional.

Dessa forma é coerente interpretar que a grande maioria dos egressos, quando ingressou no Programa, tinha como intenção atuar na área acadêmica e, ao término do curso, efetivamente alcançou o objetivo.

Dos que atuam em IES, destaca-se a atuação dos egressos na docência e em atividades correlatas (FIGURA 5). Além da atividade como docente em cursos de Graduação, são declaradas atividades relativas a pesquisa, orientação em cursos de Pós-graduação "stricto sensu” e docência em Cursos de Pós-graduação "lato sensu".

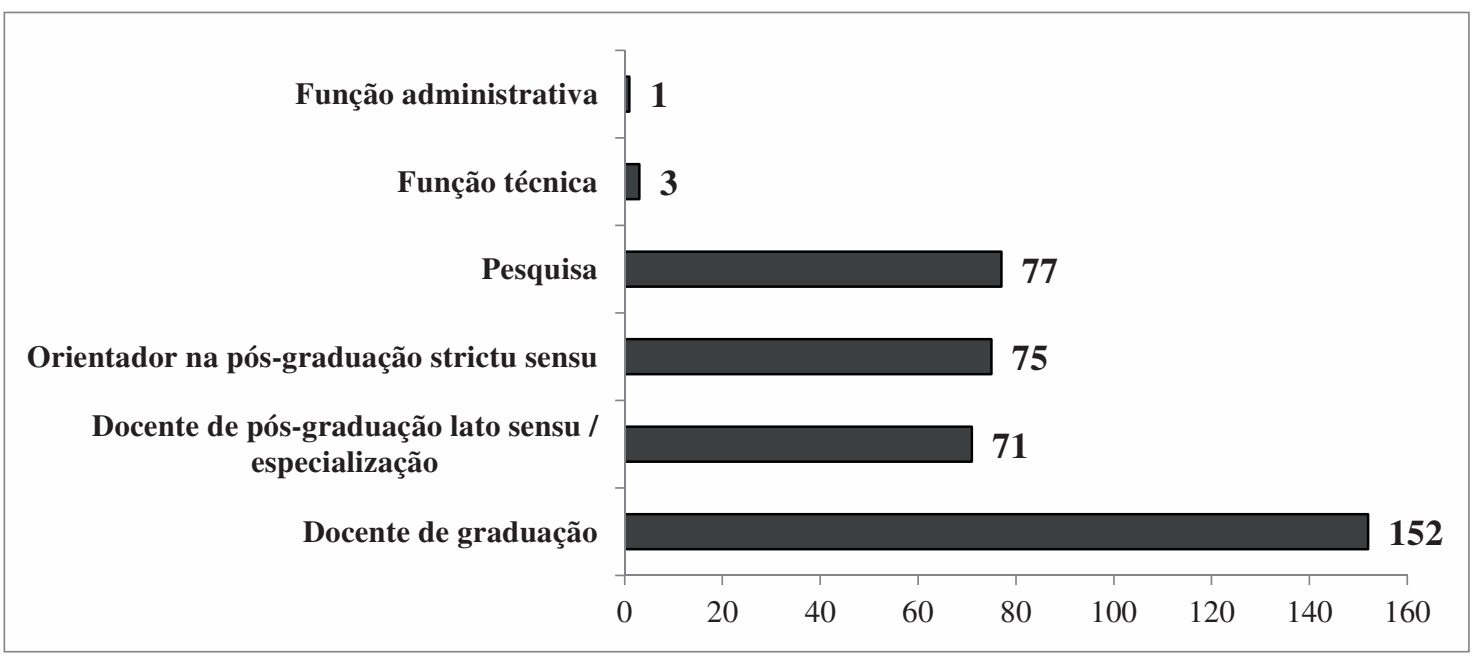

FIGURA 5 - Atividades exercidas pelos egressos nas IES. 
Quanto a cargos ocupados nas IES, os porcentuais relativos a atividades nas IES 22,7\% em atividades administrativas e 78,3\% em atividades de coordenação de cursos (de Graduação à Pósgraduação "stricto sensu") e uma forte atuação junto a grupos e laboratórios de pesquisa (FIGURA 6). Dados relativos a esse tema em 2007 revelaram que cerca de $64 \%$ dos egressos do mestrado e $84 \%$ dos egressos do doutorado desenvolveram atividades de liderança.

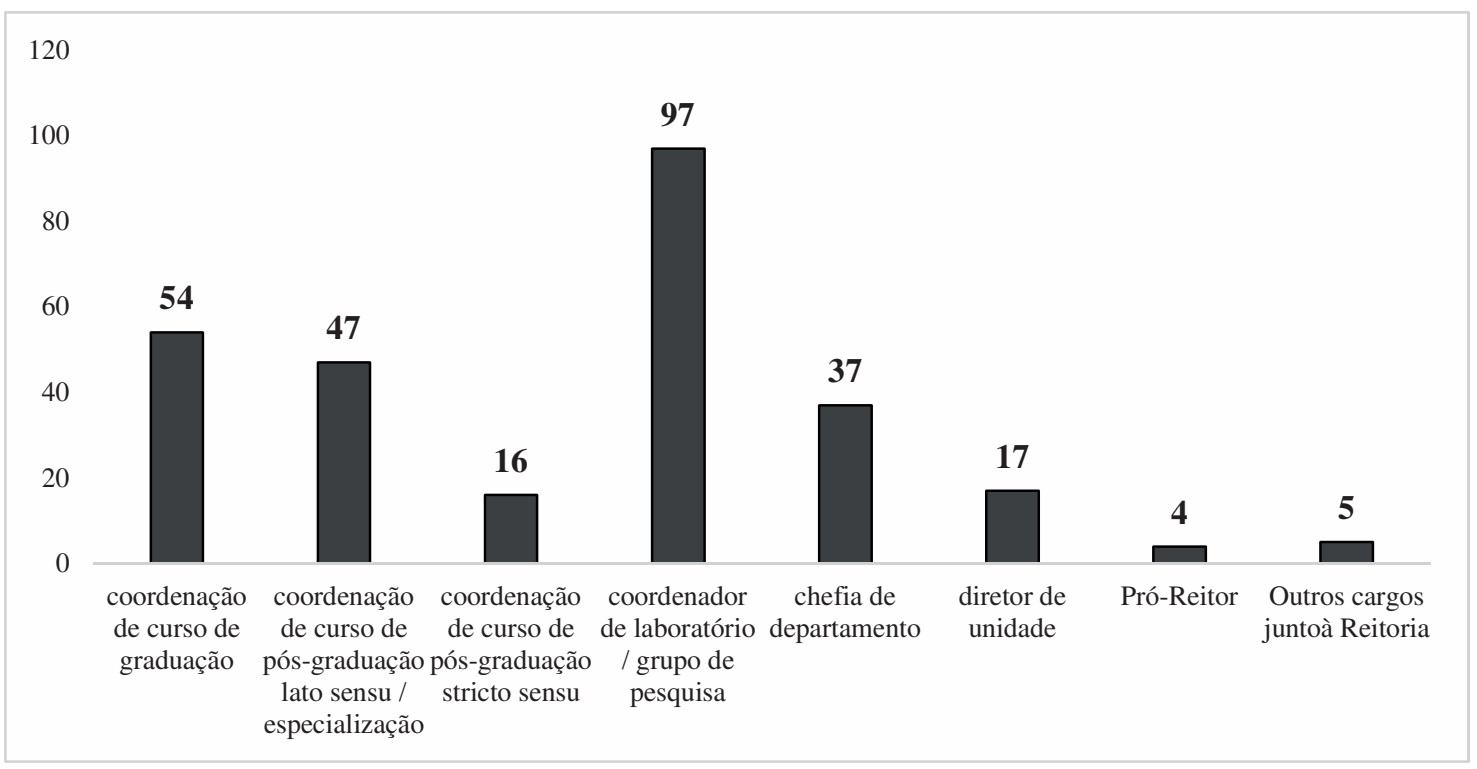

FIGURA 6 - Cargos exercidos pelos egressos nas IES.

Com base nos dados obtidos, podemos perceber que os egressos do Programa de Pós-graduação (Mestrado e Doutorado), da Escola de Educação Física e Esporte da Universidade de São Paulo (EEFE-USP), exercem atividades de docência em cursos de graduação e pós-graduação "lato sensu"/especialização, bem como atuam, também em bom número, na área de pesquisa e com a orientação em programas "stricto sensu".

Além disso, e tal fato merece destaque, o Programa de Pós-Graduação da EEFE-USP mostra, em razão dos resultados obtidos, a vocação do
Programa para a formaçáo de líderes para atuar na área acadêmica de instituiçôes públicas e privadas do país, no ensino e na pesquisa.

Pró-reitor, diretor de unidade, chefe de departamento, coordenador de cursos em diversos níveis e de laboratórios e grupos de pesquisa por todo o país, são, atualmente, ocupados por egressos do Programa de Pós-graduação da EEFE, demonstrando a competência da instituição em formar, nos últimos 40 anos, as principais lideranças da área de Educação Física e Esporte, em todo o país.

\section{Considerações finais}

Criado em 1977, o Programa de Pós-graduação da Escola de Educação Física e Esporte da Universidade de São Paulo (EEFE-USP) nasceu com o propósito manifesto de atuar no sentido da formaçáo de docentes para o ensino superior e pesquisadores de nível qualificado no campo da Educação Física e Desportos.

Por outro lado, a Coordenaçáo de Aperfeiçoamento de Pessoal de Nível Superior (CAPES), entidade que regulamenta a Pós-graduação "stricto sensu" no país, valoriza a contribuição dos cursos, em todo o território nacional, pela sua capacidade de formar docentes para atuar em Instituiçóes de Ensino Superior (IES) e trabalhar como agentes de disseminação de conhecimento em diversas regióes do Brasil.

Os dados obtidos e apresentados, pela pesquisa agora realizada junto aos egressos do Programa de 
Pós-graduação da EEFE-USP, em comemoração aos seus 40 anos de atividade, demonstram de forma clara o sucesso do Programa em atingir seu objetivo inicial e atender às determinaçóes da CAPES.

Desde sua implantação até 2016, foi formado um número significativo e de forma contínua de mestres e doutores nos programas da EEFE-USP. Expressiva parcela desses egressos atua, hoje, na docência em cursos de graduação e pós-graduação espalhados pelo Brasil. Mais significativo do que isso é o grande número de ex-alunos dos Programas de Pós-graduação da EEFE-USP que ocupam, atualmente, posição de liderança e relevância em diversos níveis da estrutura acadêmica do país.
Os egressos dos cursos de Pós-graduação da EEFE-USP, em posiçóes de influência em IES por todo o país, permite à EEFE-USP ser considerada uma das instituiçóes de ensino que mais determina o rumo do pensamento e da pesquisa nas diversas áreas do conhecimento em Educação Física e Esporte.

Tais dados também ilustram o cumprimento, de forma consistente e permanente, da missão da EEFE-USP ao criar, 40 anos atrás, seu curso de Pós-graduação, a saber: "formação e habilitação de docentes destinados ao ensino superior e pesquisadores de nivel qualificado no campo da Educação Física e Desportos".

\section{Referências}

1. Brasil. Ministério da Educação. CAPES. Documento de área 21: educação física. Brasília: MEC; 2016. [citado 28 abr. 2017]. Disponível em: http://www.capes.gov.br/component/content/article/44-avaliacao/4666-educacao-fisica.

2. Moreira EC, Tojal JBAG. Prioridades dos programas de pós-graduação stricto sensu em educação física: a visão dos egressos. Rev Bras Ciênc Esporte. 2012;35:161-78.

3. Amadio AC. Os caminhos da pós-graduação "stricto sensu”. Rev Paul Educ Fís. 1999;13(N esp):36-41.

4. CAPES. Pró-reitora de pesquisa defende análise sobre egressos da pós-graduação. Brasília: CAPES. [citado 1 maio 2017]. Disponível em: http://www.capes.gov.br/COMPONENT/CONTENT/ARTICLE/36-SALAIMPRENSA/NOTICIAS/8171PRO-REITORA-DE-PESQUISA-DEFENDE-ANALISE-SOBR E-EGRESSOS-DA-POS-GRADUACAO \%0AXXXII ENPROP\%0A.

5. Schanaider A. Sistema de mapeamento dos egressos. Rev Col Bras Cir. 2015:42:413-17.

6. FGV-OPINIÃO. Percepçóes dos egressos do mestrado acadêmico e doutorado do programa de pós-graduação em história, política e bens culturais. Rio de Janeiro: FGV. [acesso 23 abr. 2017]. Disponível em: http://cpdoc.fgv.br/sites/ default/files/cursos/posgraduacao/arq/RelatorioEgressos_MAD.pdf.

7. Universidade Federal do Paraná. Programa de pós-graduação em administração UFPR. Curitiba: UFPR. [acesso 24 abr. 2017]. Disponível em: http://www.prppg.ufpr.br/site/ppgadm/visibilidade/acompanhamento-de-egressos/.

8. Universidade de Brasília. PPG ARTE UnB. Brasília: UnB. [acesso 25 abr. 2017]. Disponível em: http://www.ppgarte. unb.br/programa/egressos.

9. Unversidade Federal da Bahia. PPG Educação. Salvador: UFBA. [acesso 24 abr. 2017]. Disponível em: http://www. pgedu.faced.ufba.br/node/3208.

10. Rissi M, Silvestre Filho J. Análise dos egressos de doutorado quanto aos requisitos para serem docentes da pós-graduação stricto sensu. XVI Coloquio Internacional de Gestión Universitaria; 2016; Arequipa, Peru. Arequipa: UFSC: 2016.

11. Parizotto JOL, Imparato JCO, Novaes TF. Perfil profissional do egresso do programa de pós-graduação em odontopediatria. Rev ABENO. 2015;15:48-54.

12. Sá MR. O egresso do programa de pós-graduação da Escola de Educação Física e Esporte da Universidade de São Paulo como fonte de informação para avaliação da qualidade do serviço [monografia]. São Paulo: Universidade de São Paulo, Escola Polítécnica; 2007.

13. Quadros HM. Mestrados na área de eduação física no Estado do Rio Grande do Sul: um estudo sobre o perfil dos egressos [dissertação]. Pelotas: Universidade Federal de Pelotas; 2012.

14. Gentil RN, Nascimento JV. Migraçáo acadêmica de doutores em educação física. XIX Congresso Brasileiro de Ciências do Esporte; VI Congresso Internacional de Ciências do Esporte; 2015; Vitoria, Brasil. Vitória: CBCE; 2015. 
Bastos FC, et al.

ENDEREÇO

Flávia da Cunha Bastos

Escola de Educação Física e Esporte - USP

Av. Prof. Mello Moraes, 65

05508-030 - São Paulo - SP - BRASIL

e-mail: flaviacb@usp.br

96 • Rev Bras Educ Fís Esporte, (São Paulo). 2017 Ago; 31(N esp):89-96. 